\title{
SERE TRAINING IMPLEMENTATION IN "NICOLAE BĂLCESCU” LAND FORCES ACADEMY
}

\author{
Daniel SOLESCU \\ "Nicolae Bălcescu” Land ForcesAcademy, Sibiu, Romania \\ danielsolescu@yahoo.com \\ Adrian TEODORESCU \\ “Nicolae Bălcescu” Land Forces Academy, Sibiu, Romania \\ teo_jordan2005@yahoo.com
}

\begin{abstract}
Modern international security environment requires that future leaders training should be polyvalent. This article aims to present the tremendous benefit that SERE training brings in Land Forces officers training and education.
\end{abstract}

KEYWORDS: Survival, Evasion, Resistance and Escape

\section{Introduction}

In the field of combat training and survival in temporary isolation conditions Land Forces Academy students conduct their training in the first year of study, no matter the military specialty they are assigned to. During the winter and summer modules, the students form and achieve specific skills in seeking, finding, and exploiting the necessary resources to live and care about themselves.

However, we consider that a land forces officer training should be more complex and consistent in the field of survival, based on his crucial role inside his unit. Thus, the junior officer ought to achieve supplementary competencies on evasion, resistance in captivity, escaping form a hostile force and returning to his own troops, using all necessary means at hand.

This particular training program has been implemented in Romania by the special operations forces - SOF, under the generic name of SERE - Survival, Evasion, Resistance and Escape.

This project starts from the idea that one of the main duty of every soldier, and officer that is being isolated by the mother unit during the combat is to continue the fight, evade the capturing, and return to the own troops.

SERE concept includes all the necessary measures, activities, and actions that should be taken by the militaries during independent combat in harsh isolated conditions in order to maintain his fighting force, survive in temporary isolation, protect against capturing, avoid the enemy, and adopt the right behavior during captivity, recovery, and returning to own troops.

Survival in temporary isolation condition consists of the assembly of all actions conducted with the purpose of staying alive, with limited resources, in every rough condition like separation from the unit, evading capturing, or being a 
prisoner in enemy custody. Survival supposes knowledge and skills in seeking, finding, and exploiting natural and artificial resources that are needed to live and care about your own.

Evasion capturing is the process in which isolated soldiers fighting in hostile terrain or in enemy occupied area conduct elusive actions in order to return in friendly area. This process is an extension of fight that could contain harassment actions too (ambush, short attacks) and is based on high combat readiness and the sense of not giving up in front of the enemy.

Resistance in captivity refers to all action conducted by solders in order to survive whenever captured by the enemy. Modern conflict experience has proved that survival and resisting to enemy interrogations challenge the physical and psychical resources of the captured soldiers; therefore, the resistance transforms itself into a fight with your own fear, seeking calm, self-control, and rationality.

Evading is whatever captured soldiers do in order to escape from that situation of being prisoner.

Knowing and perfect application of SERE Technics, tactics, and procedures (TTPs) represent the art of commander who seeks staying alive along with subordinates, returning rapidly to friendly area, physical and psychical safe.

\section{SERE Training Levels}

There are three levels generally accepted when referring to SERE (Carpiuc \& Tolea, 2016):

Level $\boldsymbol{A}$ - represents the initial level and refers to the general training session that should be added in the based military training curriculum. This level is to be attended by the entire military personnel at the beginning of their career, and it aims at familiarization with general knowledge about survival in temporary isolation as follows:
- building individual and collective temporary shelter using materials found in the area;

- building fire based on necessity and materials at hand;

- water procuring, filtering, storing, and transport;

- vegetal and animal originated food procuring, preparing, and conserving;

- building traps for small and large animals, using traction or pressure systems;

- Improvised tools and weapons manufacturing.

Level $\boldsymbol{B}-$ is designed for reconnaissance and paratroopers units that perform long range missions behind the enemy lines. It also aims to develop the competencies and to level the specific TTPson temporary isolation survival, along with maintaining the combat capacity, in order to successfully achieve the mission prior to return to the own troops.

Level $\boldsymbol{C}-$ is designed for SOF operators, long range reconnaissance units, and soldiers whose specialty and assignment poses a medium to high risk of being captured. This level aims to fully apply the specific TTPs in the following particular situations:

- operators avoid being discovered, continue the mission or return to own lines;

- operators were discovered but they avoided being captured;

- operators were captured and they managed to escape; later on, they activated the recovery plan and return to own lines by themselves.

We consider that is critically important that every land forces officer gets ready to act in temporary isolation and imprisonment. Therefore, SERE program should focus on unitary understanding of SERE concept, responsibilities, and behavior while eluding the enemy, during captivity or evading. 
SERE implementation for cadets is determined by the following factors:

- there is a great deal of risk of exploiting data that officers might have and further exploitation of sensitive data, based on the enemy evaluation;

- SERE program inflicts tremendous physical and psychical endowments that helps operators to survive;

- enable the resistance to enemy interrogation and tough questioning and manipulation used in detention;

- support future leaders to plan, organize, and conduct the escape from imprisonment;

- augment future commanders to boost soldiers 'morale in harsh conditions while operating behind enemy lines, on the way to own troops.

\section{Land Forces Academy SERE Module Planning}

Inside Land Forces Academy (LFA), designing of a new training module starts when all standard planning questions are clearly answered, as follows: audience:

a) Identifying the primary target

SERE module targets LFA students from the $2^{\text {nd }}$ year of study.

b) What is the level of expertise and knowledge in the domain?

Students have passed survival in temporary isolation module, both on winter and summer time.

c) What are the training final objectives?

- Foundation, development, and evaluation of physical abilities and stress reaction during temporary isolation condition or captivity.

- Footing and enlargement of all necessary skills for surviving in temporary isolation or captivity conditions.

- Underpinning and extension of practical and intellectual abilities for escaping planning and execution, as well as for returning to own troops' lines.

- Broadening the skills for concealing sensitive equipment that might be useful when in captivity or plan to escape.

- Development of solid communication skills that are necessary to contact own aviation or other support elements in the area, as well as other individuals (military or civilian) met in captivity.

d) What are the disciplines in the SERE curriculum?

- Specific action training: specific procedures while travelling in an enemy controlled terrain, counter interrogation training, gestures communication while in imprisonment, eluding procedures while being under surveillance of enemy specialized units.

- Survival training: first aid training, land navigation training, survival in temporary isolation conditions.

- Military physical education: maintaining a strong physical conditions at combat unit level standards, refine the physical disciplines in order to contribute to combat skills development, improvement of body-to-body close combat individual skills, education of morale and willingness that drives the fighter in combat: courage, tenacity, perseverance, self-control (Stănciulescu, 2015).

e) Are there human and material resources to design and run this course?

I. Personnel: $1 \mathrm{x}$ specialized officer instructor/platoon, 1 x platoon commander, $3 \times$ NCO specialists/platoon, $1 \mathrm{x}$ medic, $1 \mathrm{x}$ truck driver, $1 \mathrm{x}$ van driver; 


\section{Materials:}

Equipment: Battle dress uniform in bad condition, used boots, campaign cutlery, water bottles, camouflage tent sheets

Food: ratios for two training days, cold dishes;

Vehicles: $1 \mathrm{x}$ truck, $4 \mathrm{x} 4$ vehicle.

f) What are the practical activities fulfilled by the students?

- Build the individual survival kit, used later within the exercise.

- Build an improvise water filter.

- Build three typed of traps.

- Build two hand tools and three improvised weapons from materials at hand in the environment.

- Build three types of fire.

- Build four temporary shelters (summer and winter type).

- Carry water with improvised recipients.

- Build a litter in order to carry a wounded soldier.

- Conceal small equipment that is necessary for survival.

- Draw two sheets with international codes for signaling and gestures used in communication.

- Write an individual escape plan.

- Build different bandages.

g) What is the evaluation strategy?

The students' evaluation is conducted on regular basis by permanent observation by the trainers. During temporary imprisonment, there will be 24 hours monitoring with $\mathrm{GO} / \mathrm{NO} \mathrm{GO}$ score for every stage. Also, students are to be evaluated on their way to friendly troops' lines after escape, with the help of specialized units of Ministry of Administration and Internal Affairs (MAI).

\section{SERE Module Running}

In order to maximize the results, three phases plan is to be run:

Phase One - Action training (40 hours) as follows:

a. Theoretical training ( 8 hours) aims to achieve the knowledge about the activities behind enemy lines. At this point, students are taught about the code of conduct that should obey in imprisonment situations. The "code of conduct" traits those specific likely situations met in captivity; it helps to honorably survive and resist the enemy exploitation. These lessons are held in class with the help of different methods (case study, conversation) and materials (video, documents, and manuals);

b. Practical training ( 36 hours) aims to train the students to following procedures: travelling in enemy controlled area, survival in temporary isolation, countering enemy interrogation, gesture communication, evading the enemy surveillance. Every training day starts with physical training module that follows the improvement of body-to-body close combat individual skills and a high level of physical resistance, according with LFA standards. (Stănciulescu, 2016)

During first phase, in order to achieve the objectives and to simulate the reality of harsh battlefield, some of the following will be considered:

- even though some activities will be lengthened, they will not exceed 14 hours per day;

- complementary activities will be enforced all day long: movements, security, land navigation, camouflage, and trace cleaning;

- the activities won't harm physical and psychical integrity of the students.

Phase Two - takes two continuous days, based on situational training exercises, in the field of survival and evading. This phase takes place in a remote area with dense forest and vegetation. Critical for this stage is the help of gendarmerie and trace dogs, that makes the training more realistic. Thus, students should avoid local population, provide food and water, and reach their destination where they should complete some survival tasks, just for evaluation. The main purpose of this phase is leveling the physical and 
psychical resistance. Over the itinerary, most of the students will be captured and secretly transported to a hidden location where captivity conditions starts.

Phase Three - takes 24 hours. The action takes place inside a Prisoner of war (POW) camp that display low living standard conditions, forced labor, poor food, long interrogations, and little sleep. The trainer will employ various questioning and interrogation techniques, based on his imagination, initiative, and experience.

Due to the fact that the challenge for the students is at its highest point, a medic and a psychologist should be present on the spot. At this point, students learn how to resist to any informational exploitation from the adversary. One major gain is that students will quickly realize that working together, as a team, multiplies their chances to survive in captivity.

Phase Four - This stage starts in the morning of the second day of captivity. With the chance of POW camp security negligence, students will escape with few materials, and will try to reach a final point that was previously delivered in a sealed envelope. This exam is a $\mathrm{GO} / \mathrm{NO} \mathrm{GO}$ type.

Finally, an after action review would inform every students and the group about how the code of conduct was followed. This would offer a realistic picture about the behavior during imprisonment, and would also clarify some reaction drills whenever in further captivity.

During situational training exercises, trainers have the freedom of inserting new actionable situations or to supplement the time for the exercise.
Also, trainers will persuade stressful conditions by shortening the resting time, limiting food ratio and comfort, requiring high performances, and exaggerating the enemy capacity to act.

\section{Conclusion}

There is little literature about SERE excepting SOF manuals. US Army displays at least four doctrines, two manuals (FM 21-26 and FM 21-28), and four SERE training programs, for each armed force category.

The basing and development of future land forces officers has among many others the objective of influencing in a positive way and shaping the psychical process in order to create the inner security feeling and self - control, no matter how complex the environment might be.

SERE program targets emotional stabilization of individuals and groups, by creating edge situations that trigger students to followings:

- to live emotional and affective experiences close to harsh reality of the battlefield;

- to reach that psychical force that retain control over own feeling and emotions;

- to manage all fears (loneliness, darkness, unknown, closed spaces);

- to manage the limit situations, the fury and hostility.

In other words, these limit situations will enrich the officers' live experience, and resistance to stressful conditions, gaining more self-acknowledgment.

\section{REFERENCES}

Carpiuc, G. \& Tolea, G. (2016). Survival in isolation condition in different environment. Evading, Resistance, Escaping and Recovery. Paratroopers Magazine, Vol. XVII, No. 30 (39).

Stănciulescu, R. (2015). Military physical education - Formative aspects within NATO integration context. Sibiu: "Nicolae Bălcescu" Land Forces Academy.

Stănciulescu, R. (2016). Military physical education evaluation study at Nicolae Bălcescu Land Forces Academy. Sibiu: "Nicolae Bălcescu” Land Forces Academy. 